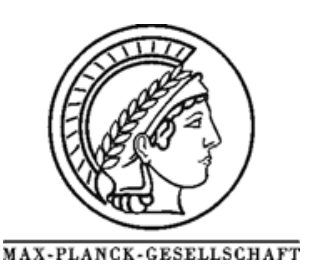

\title{
In Situ Spectroscopic Investigation of Activation, Start-Up and Deactivation of Promoted Sulfated Zirconia Catalysts
}

\author{
B.S. Klose ${ }^{a}$, F.C. Jentoft ${ }^{a}{ }^{*}$, P. Joshi ${ }^{a}$, A. Trunschke ${ }^{a}$, R. Schlögl ${ }^{a}$, I.R. Subbotina ${ }^{b}$, V.B. Kazansky ${ }^{b}$ \\ ${ }^{a}$ Department of Inorganic Chemistry, Fritz-Haber-Institute of the MPG, Faradayweg 4-6, 14195 Berlin, Germany \\ ${ }^{b}$ N.D. Zelinsky Institute of Organic Chemistry, Russian Academy of Sciences, \\ Leninsky Prospect 47, Moscow 117913, Russia
}

${ }^{*}$ Corresponding author: e-mail jentoft@,fhi-berlin.mpg.de, fax: +49-30-84134693, phone: +49-30-84134408

Available online 27 June 2006

\begin{abstract}
Sulfated zirconia (SZ), unpromoted and promoted with $0.5-2.0 \mathrm{wt} \% \mathrm{Mn}$ or Fe, was investigated by in situ IR and UV-vis spectroscopy during activation at $723-773 \mathrm{~K}$ and interaction with $n$-butane at $298-323 \mathrm{~K}$. During start-up of the catalysts, the isomerization rate increases with the amount of water that is being formed, consistent with an activation of $n$-butane via oxidative dehydrogenation. Sulfate is the most likely oxidizing agent because activity is also observed for unpromoted SZ and without reduction of Mn. Isomerized species were also found on the surface of Fepromoted SZ after exposure to $n$-butane without water formation indicating other yet unknown initiation pathways. During isomerization, Lewis acid sites on Fe-promoted $\mathrm{SZ}$ are blocked by water; the valence of $\mathrm{Mn}$ decreases only if the catalyst was previously activated in $\mathrm{O}_{2}$. Stable species absorbing at 2820-2840 $\mathrm{cm}^{-1}$ detected on the surface of SZ and Fe-promoted SZ after contact with $n$-butane at $298 \mathrm{~K}$ are tentatively ascribed to alkoxides, which may be side-products or intermediates. These species differ slightly for the two catalysts, reflecting the different structural and electronic properties of the materials.
\end{abstract}

Keywords: IR spectroscopy, UV-vis spectroscopy, diffuse reflectance, in situ, promoted sulfated zirconia, butane isomerization, catalyst deactivation

\section{Introduction}

Sulfated zirconia (SZ) is an attractive catalyst for low temperature alkane isomerization [1,2]. Its activity for butane conversion can be improved by $1-2$ orders of magnitude through addition of iron or manganese cations, which exert a comparable promotional effect [3-6]. Initially SZ was believed to be a solid superacid [1] whose acidity could be further increased through promoters [7]. Except for the extraordinary catalytic activity and Hammett indicator methods [1], no other indications for superacidity were found. The alleged effect of the promoters on the acid strength originated from misleading data, and in fact most researchers could not find higher acid site strength or density after addition of Fe or Mn [8-10]. It was then proposed that promoters facilitate reaction initiation via oxidative dehydrogenation (ODH) to butenes, which may be converted into the reaction chain carriers, viz. carbenium ions. Evidence was indirect, such as better activity after activa- tion in oxidizing rather than in inert atmospheres $[11,12]$. Iron (IV) oxy species were held responsible for the oxidation by Wan et al. [11]. Song and Kydd speculated that sulfate might provide the redox capability on SZ, which shows equal performance after activation in air or helium [12]. If differences exist in the initiation pathway for SZ and promoted SZ, they are not reflected in the product distributions obtained in the conversion of small hydrocarbons: with increasing temperature, skeletal isomerization, disproportionation, oligomerization and cracking products are observed for SZ and its promoted forms [2,13,14]. Promoted catalysts show higher activity at lower temperatures but activation energies for butane isomerization are similar; and $\mathrm{Hsu}$ et al. speculated that promotion increases the number of active sites rather than change their quality [3], consistent with the reports showing no increase in acid strength through promotion by $\mathrm{Fe}$ and $\mathrm{Mn}$.

Lately, evidence has been accumulating that at least one pathway for butane activation on SZ catalysts is indeed ODH. Water has been detected by in situ IR spectroscopy, 
and the isomerization rate during the induction period has been found to be proportional to the amount of water formed [6,15]; this correlation applies for SZ and Mnpromoted SZ. During and after reaction at higher temperatures $(423-573 \mathrm{~K})$ unsaturated hydrocarbons were spectroscopically detected on the surface of SZ [16,17]; and butene was inferred to desorb in TPD experiments [15]. The oxidizing agent in the unpromoted case appears to be sulfate; reduced S-containing species evolve, albeit at higher temperatures: at $673 \mathrm{~K} \mathrm{SO}_{2}$ [15] or at 523-573 K $\mathrm{H}_{2} \mathrm{~S}[17,18]$. Reduced S-O species, specifically dithionate, have only been detected on the surface of SZ after exposure of SZ to isobutyraldehyde [19]. For the promoted systems, reports on valence changes upon contact with feed differ: Millet et al. [20] reported reduction of Fe during reaction, while Mn was not reduced [21,22] or reduced in a way uncorrelated to performance [22].

According to the ODH hypothesis, isomerization on SZ materials would be initiated by a stoichiometric reaction. However, SZ may still act as a catalyst, because once the "sites" are activated, theoretically, an infinite number of turnovers is possible. It is assumed that upon contact with the feed, hydrocarbon surface species are formed via ODH and subsequent protonation. These species would be surface-equivalents of carbenium ions as exist in solutions and serve as chain carriers. Deactivation may occur if intermittently formed butenes polymerize on the surface or if isomerization or hydride transfer do not proceed properly and side products are formed. It has been proposed that water acts as a poison $[23,24]$ or sulfate is lost, but once the site is activated this may not matter.

It is unresolved how the surface reactivity is related to the zirconia solid state chemistry. Although sulfated monoclinic zirconia is catalytically active [25], the tetragonal phase is necessary for very good activity. On the other hand, not every tetragonal zirconia is highly active [26], indicating intrinsic variations in the phase are important. The promoters, $\mathrm{Mn}$ or $\mathrm{Fe}$, are dissolved in the zirconia lattice and stabilize the tetragonal phase [5]. The fraction of surface and lattice promoter species depends on the promoter content and the preparation method, with Fe having a higher propensity to remain on the surface than Mn [5]. Solid solutions of Fe in zirconia were also inferred by Yamamoto et al. [21], Ohtsuka [27], and Xavier et al. [28]. These solid state phenomena have yet to be connected to the performance.

The goal of this paper is to complete the picture on reaction initiation and deactivation for $\mathrm{SZ}$ in comparison to $\mathrm{SZ}$ promoted with $\mathrm{Fe}$ or $\mathrm{Mn}$. We investigate the effect of the pretreatment atmosphere on Mn-promoted SZ by in situ UV-vis spectroscopy, measure the water accumulation during the start-up of butane isomerization on Fe-promoted sulfated zirconia by in situ IR spectroscopy, and describe surface hydrocarbon species formed during the reaction. Causes for deactivation are sought by in situ UV-vis spectroscopy and probing the sites after interruption of the reaction. In the discussion, we shall address similarities and differences between unpromoted and promoted SZ and possible relations between solid-state and surface chemistry in order to develop a unified model for all SZ catalysts.

\section{Experimental}

\subsection{Catalyst Preparation}

Dried $(21 \mathrm{~h}, 383 \mathrm{~K})$ sulfated zirconium hydroxide (MEL Chemicals XZO 682/01) was used as precursor. Samples promoted with 0.5 or $2.0 \mathrm{wt} \%$ iron or manganese ("0.5MnSZ", "2.0MnSZ", "2.0FeSZ") were prepared from dried precursor according to the "incipient wetness" impregnation method, using aqueous solutions of either $\mathrm{Fe}(\mathrm{III})$ or $\mathrm{Mn}$ (II) nitrates (both Merck, p.a.), followed by drying for at least $24 \mathrm{~h}$ at room temperature. The raw materials were calcined in a $17.1 \mathrm{ml}$ quartz boat under a 200 $\mathrm{ml} \mathrm{min}{ }^{-1}$ synthetic air flow at $823 \mathrm{~K}(\mathrm{SZ})$ or $923 \mathrm{~K}$ for $3 \mathrm{~h}$ (3 $\mathrm{K} \mathrm{min}^{-1}$ nominal heating rate) $[29,30]$.

\subsection{UV-vis-NIR spectroscopy}

Spectra were acquired in situ using a Perkin-Elmer Lambda 9 spectrophotometer, equipped with a Harrick Praying Mantis ${ }^{\mathrm{TM}}$ diffuse reflectance attachment type DRA-4-PE7 and a HVC-DR3 reaction chamber. About $160-200 \mathrm{mg}$ of catalyst were supported on a stainless steel grid. The reflectance reference material was Spectralon ${ }^{\circledR}$ (UV-vis-NIR).

\subsection{IR spectroscopy}

In situ diffuse reflectance IR (DRIFT) spectra during $n$-butane adsorption and reaction were recorded with a Nicolet "Impact 410" FTIR spectrometer using a mercury cadmium telluride (MCT) detector. A further development of the DRIFTS attachment described by Kazansky et al. [31], which uses only two mirrors to focus the IR beam onto the sample, was arranged in the beam path. The catalyst powder was pressed at $100 \mathrm{hPa}$ for $2 \mathrm{~s}$, sieved into fractions of $0.2-0.5 \mathrm{~mm}$, and placed in a quartz cell equipped with a $\mathrm{CaF}_{2}$ window. Samples touched the window, hence the beam path through the gas phase was limited to the void space within the catalyst bed, and gas phase contributions were minimized. The activation sequence consisted of drying in vacuum, oxidizing at $723 \mathrm{~K}$, and finally evacuating at $773 \mathrm{~K}$ [17]. $\mathrm{CaF}_{2}$ powder was used for background measurements. Spectra with $4 \mathrm{~cm}^{-1}$ resolution were recorded at room temperature and processed with OMNIC $^{\mathrm{TM}}$ software. For all spectra, the reflectance with respect to $\mathrm{CaF}_{2}$ was converted into Kubelka-Munk units, setting the reflectance at $5000 \mathrm{~cm}^{-1}$ to a value of 0.9 .

In situ transmission IR spectra during isomerization and of adsorbed $\mathrm{CO}$ were acquired with a Perkin-Elmer System 2000 spectrometer, using a deuterated triglycine sulfate (DTGS) detector and Spectrum ${ }^{\mathrm{TM}}$ software. A high 
temperature cell $\left(\mathrm{T}_{\max }\right.$ in beam $623 \mathrm{~K}$ [32]) with two $\mathrm{CaF}_{2}$ windows connected to a vacuum and gas dosing system was placed in the sample compartment of the spectrometer. Powders were pressed into self-supporting wafers $(20 \mathrm{~s}$ at $250 \mathrm{MPa}$ ) with a specific mass of $24-32 \mathrm{mg} \mathrm{cm}^{-2}$. For activation, wafers were transferred within the closed system into a heatable section $\left(T_{\max }=823 \mathrm{~K}\right)$. CO was adsorbed on the activated catalyst and after $n$-butane isomerization. The reaction was stopped at different stages of catalytic activity by purging with $\mathrm{N}_{2}$ until bands of butane were no longer detectable. The whole system was then evacuated by a turbomolecular pump (Pfeiffer, Balzers) for $1 \mathrm{~h}$ to a total pressure below $10^{-6} \mathrm{hPa}$ before $\mathrm{CO}$ was dosed at room temperature via a variable leak valve (Varian). Spectra were converted into decadic absorbance.

\subsection{Reaction conditions and product analysis}

Catalytic experiments were conducted in flow at atmospheric pressure. Activation was carried out at nominal $723 \mathrm{~K}$ (transmission IR) or $773 \mathrm{~K}$ (UV-vis-NIR) in $20-40$ $\mathrm{ml} \mathrm{min}{ }^{-1}$ inert $\left(\mathrm{N}_{2}\right.$ or $\left.\mathrm{He}\right)$ or oxidizing atmosphere. Reactions were conducted at $323 \mathrm{~K}$ at $1-5 \mathrm{kPa} n$-butane and flows between 20 and $30 \mathrm{ml} \mathrm{min}^{-1}$. Product analysis for IR and UV-vis-NIR experiments was performed by on-line gas chromatography (Varian 3800, flame ionization detection).

\section{Results}

\subsection{UV-Vis-NIR spectroscopy}

The diffuse reflectance spectrum of calcined $0.5 \mathrm{MnSZ}$ shows a strong charge transfer band centered at $320 \mathrm{~nm}$ and at least two overlapping d-d transition bands at approximately 555 and $690 \mathrm{~nm}$ (Figure 1). During activation in $\mathrm{He}$, the bands at 320 and $690 \mathrm{~nm}$ lose intensity while absorption increases between 450 and $550 \mathrm{~nm}$. The spectrum of the activated catalyst shows increasing absorption with increasing wavelength in the visible range and a small maximum at about $410 \mathrm{~nm}$ (Figure 1a). During activation in $\mathrm{O}_{2}$, the band at $690 \mathrm{~nm}$ decreases in intensity and is shifted towards the band at $555 \mathrm{~nm}$. After cooling to reaction temperature $(323 \mathrm{~K})$ the spectrum resembles that measured before activation, except the band at $555 \mathrm{~nm}$ is more intense (Figure 1b).

In the NIR region, bands at $1425 \mathrm{~nm} \approx 7020 \mathrm{~cm}^{-1}$ and $1920 \mathrm{~nm} \approx 5210 \mathrm{~cm}^{-1}$ arise from the overtone of the $\mathrm{OH}$ stretching vibration and a combination of $\mathrm{OH}$ stretching and deformation modes, respectively (not shown). These bands are diminished during the heat treatment, independent of the activation atmosphere.

Differently activated $0.5 \mathrm{MnSZ}$ samples were tested for $n$-butane isomerization; catalytic data corresponding to the states achieved at the end of activation (Figure 1) are shown in Figure 2. All rate vs. time-on-stream profiles are a)

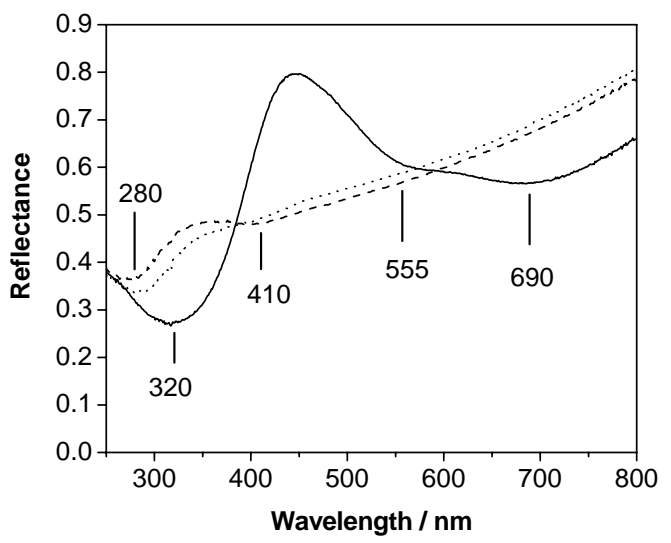

b)

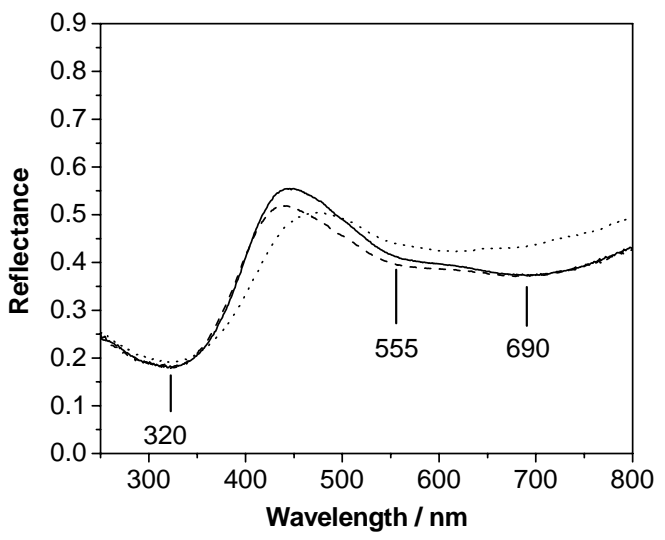

Figure 1: UV-vis spectra of $0.5 \mathrm{MnSZ}$ before activation (solid line), at $773 \mathrm{~K}$ (dotted line), and after cooling to 323 $\mathrm{K}$ (dashed line): a) in $20 \mathrm{ml} \mathrm{min}-1 \mathrm{He}$; b) in $20 \mathrm{ml} \mathrm{min}^{-1} \mathrm{O}_{2}$.

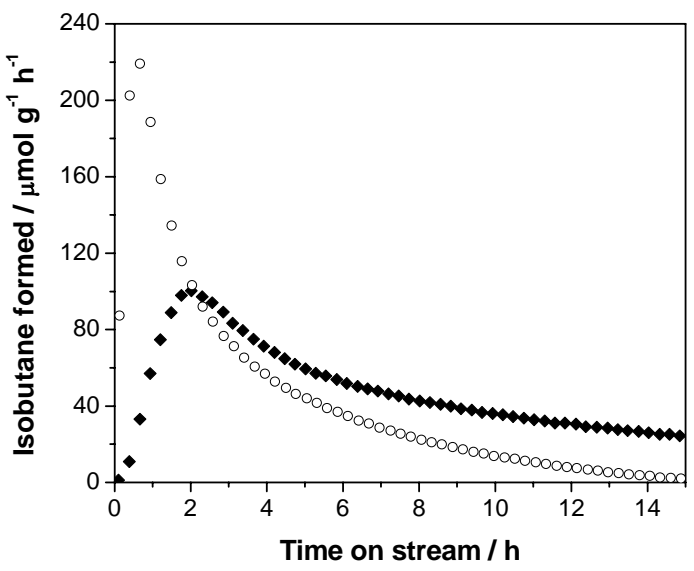

Figure 2: Rate of $n$-butane isomerization vs. time on stream after activation in $20 \mathrm{ml} \mathrm{min}^{-1} \mathrm{He}$ (solid diamond) or $\mathrm{O}_{2}$ (open circle). Conditions: $191 \mathrm{mg} 0.5 \mathrm{MnSZ}$ (He activation) or $199 \mathrm{mg} 0.5 \mathrm{MnSZ}\left(\mathrm{O}_{2}\right.$ activation), $323 \mathrm{~K}$, feed: $5 \%$ $n$-butane in $\mathrm{N}_{2}\left(20 \mathrm{ml} \mathrm{min}^{-1}\right)$, activated at $773 \mathrm{~K}$ for $30 \mathrm{~min}$ ( $5 \mathrm{~K} \mathrm{~min}^{-1}$ heating ramp).

characterized by an induction period with increasing conversion until a maximum is reached. Activation in $\mathrm{O}_{2}$ leads to a higher maximum conversion (ca. $220 \mu \mathrm{mol} \mathrm{g} \mathrm{g}^{-1} \mathrm{~h}^{-1}$, 
reached after $1 \mathrm{~h}$ ) followed by a faster deactivation of the catalyst than activation in $\mathrm{He}$ (maximum conversion ca. $100 \mu \mathrm{mol} \mathrm{g}{ }^{-1} \mathrm{~h}^{-1}$, reached after $2 \mathrm{~h}$ ). The respective UV-vis spectra recorded in situ are shown in Figure 3. For the catalyst that was activated in He (Figure 3a), the spectrum taken after $15 \mathrm{~h}$ on stream does not differ from that taken before the start of reaction. After activation in $\mathrm{O}_{2}$, the spectra of the $0.5 \mathrm{MnSZ}$ catalyst change during this period of time (Figure 3b); a difference spectrum after conversion into Kubelka-Munk units reveals formation of a band at $410 \mathrm{~nm}$ and decreasing absorption at ca. 340 and $685 \mathrm{~nm}$.

a)

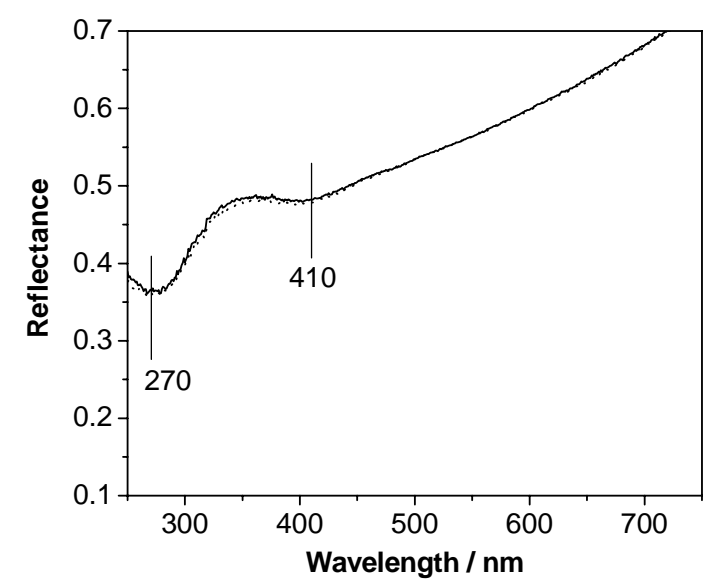

b)

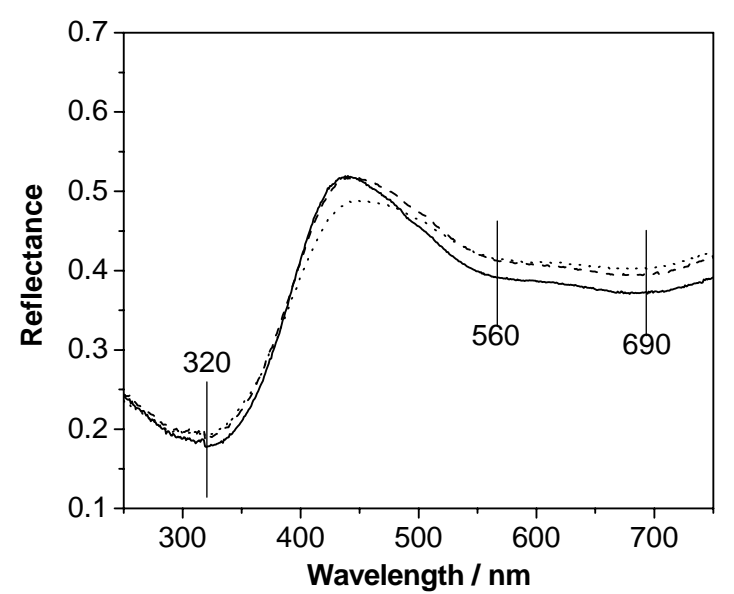

Figure 3: UV-vis spectra of $0.5 \mathrm{MnSZ}$ recorded in situ before reaction (solid line), $7 \mathrm{~h}$ on stream (dashed line), or $15 \mathrm{~h}$ (dotted line) on stream: a) previously activated in 20 $\mathrm{ml} \mathrm{min}{ }^{-1} \mathrm{He}$; b) previously activated in $20 \mathrm{ml} \mathrm{min} \mathrm{m}^{-1} \mathrm{O}_{2}$. Conditions: 191 or $199 \mathrm{mg}$ 0.5MnSZ, $323 \mathrm{~K}$, feed: $5 \mathrm{kPa}$ $n$-butane in balance of $\mathrm{N}_{2}$ with total flow $20 \mathrm{ml} \mathrm{min}^{-1}$, activated at $773 \mathrm{~K}$ for $30 \mathrm{~min}$ ( $5 \mathrm{~K} \mathrm{~min}^{-1}$ heating ramp).

\subsection{Diffuse reflectance infrared spectroscopy: $n$ - butane adsorption and reaction}

Figures $4 a$ and $4 b$ show DRIFT spectra of SZ and $2.0 \mathrm{FeSZ}$ in the activated state in vacuum, during contact with $100 \mathrm{hPa} n$-butane at room temperature, and after subsequent evacuation. In the $\mathrm{OH}$ stretching region, the band at about $3633 \mathrm{~cm}^{-1}$ shifts to lower wavenumbers upon adsorption of $n$-butane for both catalysts. The additional band at $3485 \mathrm{~cm}^{-1}$ of unpromoted SZ seems not to be affected. After evacuation, the spectra of SZ and 2.0FeSZ still exhibit bands in the $\mathrm{CH}$ stretching regime, and these adsorbate vibrations differ from those of the free butane molecule. The absorption around $2880 \mathrm{~cm}^{-1}$ has a higher relative intensity than is typical for the butane gas, and for SZ is split into two bands at 2883 and $2876 \mathrm{~cm}^{-1}$; this splitting was also observed at low butane coverages on 2.0FeSZ. For SZ, two bands that do not exist in the gas phase spectrum are observed at 2840 and $2830 \mathrm{~cm}^{-1}$. Correspondingly, a broad absorption centered at $2820 \mathrm{~cm}^{-1}$, consisting of more than one band, is detected for $2.0 \mathrm{FeSZ}$. A band at $2909 \mathrm{~cm}^{-1}$ is unique to the adsorbate on $2.0 \mathrm{FeSZ}$. Also the shift of the OH-band is not completely reversible for 2.0FeSZ; however, insufficient evacuation cannot be excluded. Contact with butane does not result in a detectable increase of the absorption in the ranges 1600-1630 $\mathrm{cm}^{-1}$ or $5225-5235 \mathrm{~cm}^{-1}$ (SZ and 2.0FeSZ).

In an attempt to see if other, weakly adsorbed, species are detectable in presence of $n$-butane, but to avoid any interference of gas phase bands, spectra were recorded at only $12 \mathrm{hPa}$. Figure $4 \mathrm{c}$ shows a spectrum of $n$-butane adsorbed on $2.0 \mathrm{FeSZ}$ after subtraction of the spectrum of the activated catalyst in vacuum. The adsorbed state is characterized not only by a different pattern but also by broader bands in comparison to the narrow rotation-vibrational bands of gaseous butane (also shown). The intensity of the asymmetric $\mathrm{CH}_{3}$ vibration at $2966 \mathrm{~cm}^{-1}$ is decreased relative to the asymmetric $\mathrm{CH}_{2}$ vibration at $2940 \mathrm{~cm}^{-1}$. The corresponding symmetric $\mathrm{CH}$ vibrations appearing between 2885 and $2875 \mathrm{~cm}^{-1}$ are more intense and red-shifted with respect to the gas phase feature at $2887 \mathrm{~cm}^{-1}$. Furthermore, bands appear at 2909 (very weak) and $2830 \mathrm{~cm}^{-1}$ (weak). The overtone of the $\mathrm{S}=\mathrm{O}$ stretching vibration at $1402 \mathrm{~cm}^{-1}$ is shifted from 2765 (negative band in difference spectrum) to $2745 \mathrm{~cm}^{-1}$. 
a)
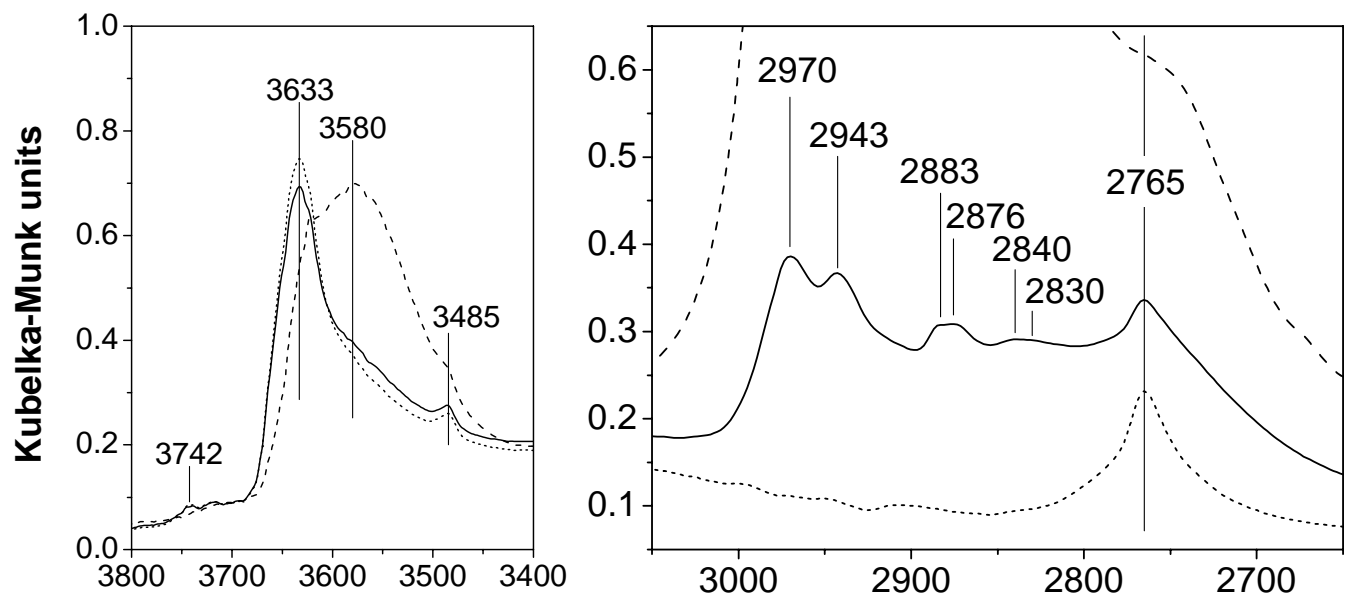

Wavenumber $/ \mathrm{cm}^{-1}$

b)
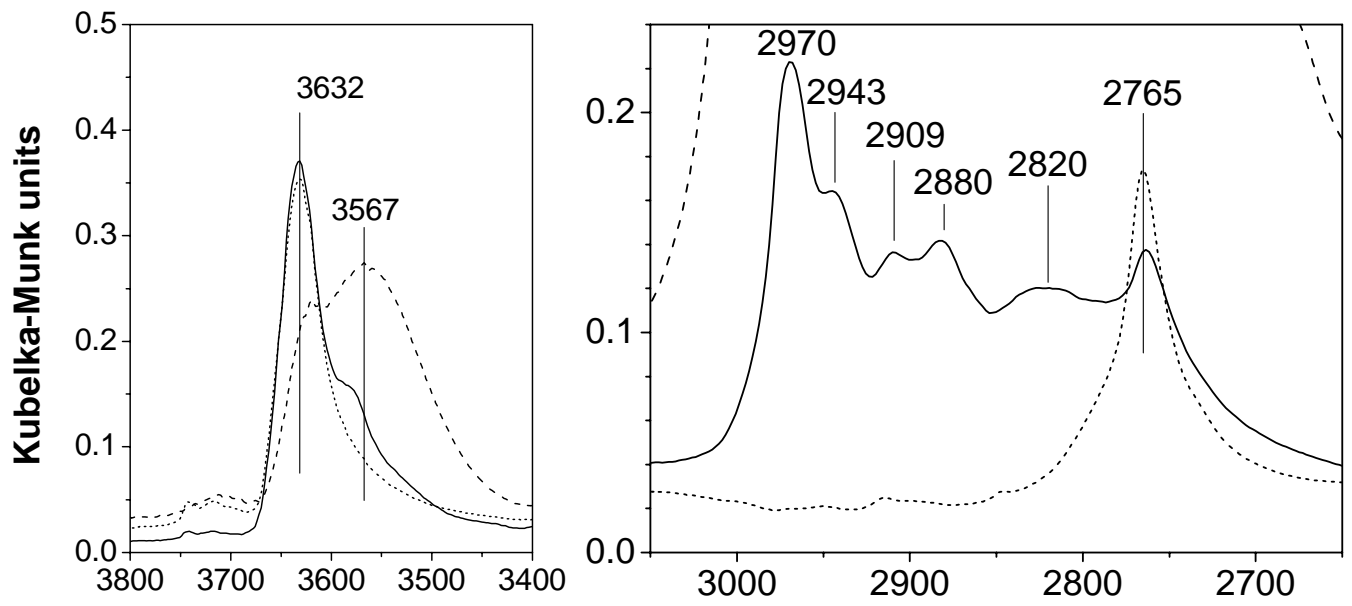

Wavenumber $/ \mathrm{cm}^{-1}$

c)

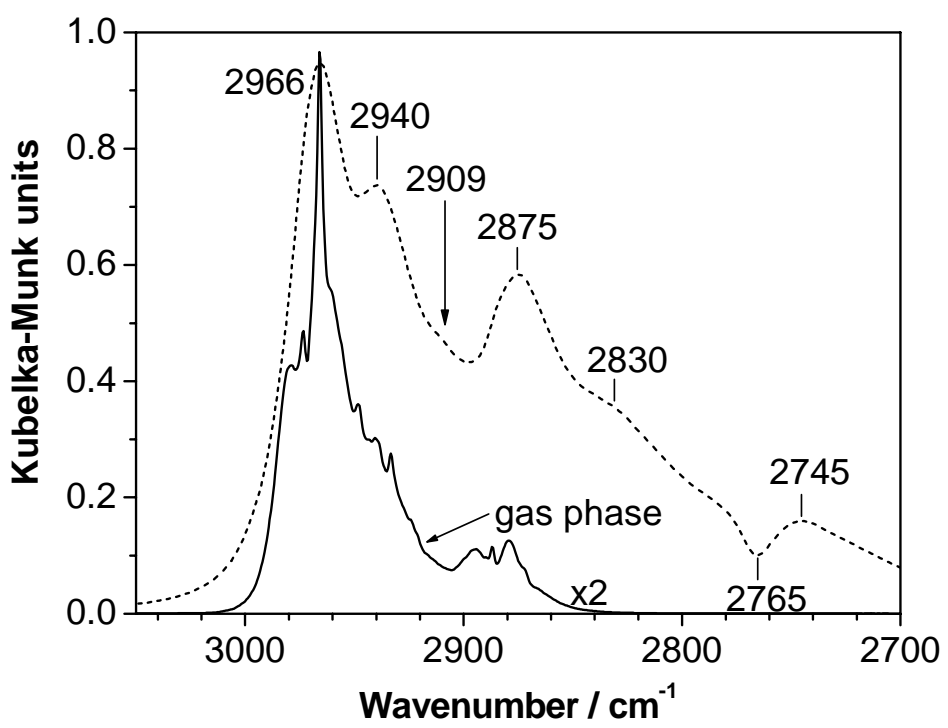

Figure 4: DRIFT spectra recorded at room temperature: a) SZ and b) 2.0FeSZ after activation (dotted line), in presence of 100 hPa $n$-butane (dashed line) and after subsequent evacuation (solid line); c) difference spectra of $12 \mathrm{hPa} n$-butane (dashed line) adsorbed on 2.0FeSZ recorded at room temperature (spectrum of activated 2.0FeSZ subtracted) and spectrum of gas phase $n$ butane (solid line). 


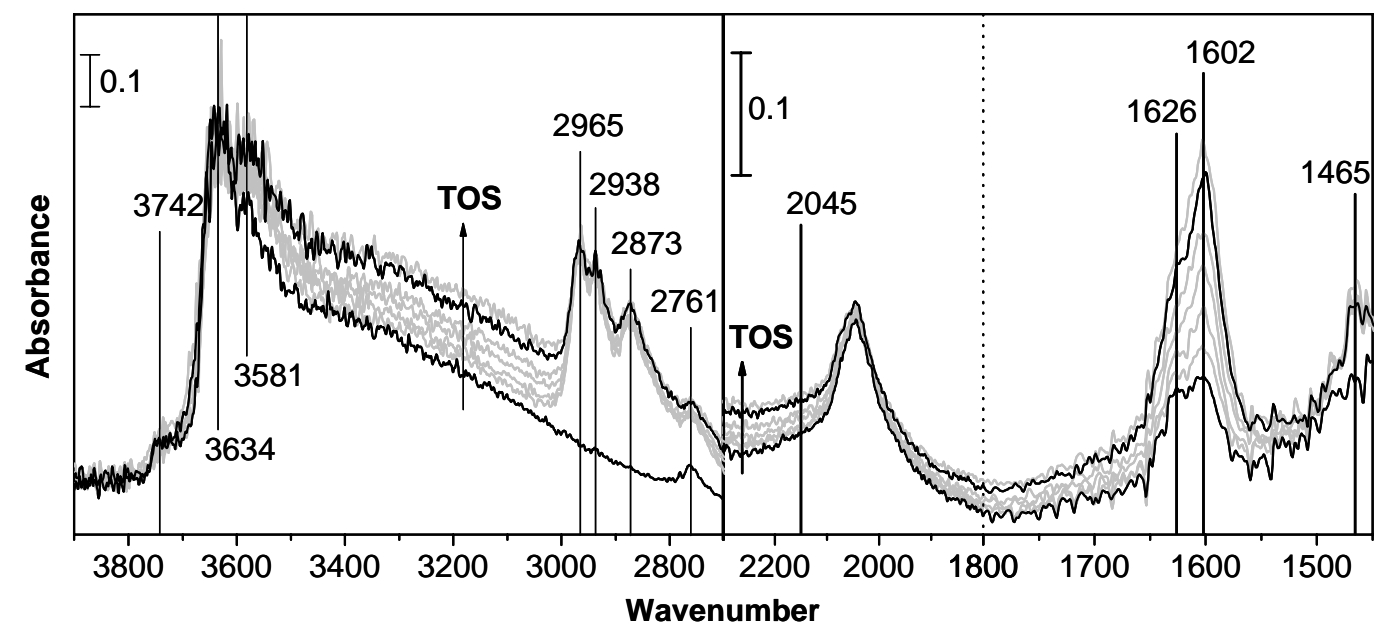

Figure 5: FTIR spectra of 2.0FeSZ taken in situ every 16 min during $n$-butane isomerization at $323 \mathrm{~K}(1 \mathrm{kPa} n$-butane in balance of $\mathrm{N}_{2}$ with total flow $30 \mathrm{ml} \mathrm{min}^{-1}$ ) after activation in $40 \mathrm{ml} \mathrm{min}^{-1} \mathrm{~N}_{2}$. Black: Spectra before start of reaction and at maximum rate.

\subsection{Transmission IR spectroscopy: n-butane reaction and $\mathrm{CO}$ adsorption}

The 2.0FeSZ wafer prepared for transmission IR experiments is active for $n$-butane isomerization after activation in $\mathrm{N}_{2}$ and shows a catalytic profile with a maximum in conversion after $1.5-2 \mathrm{~h}$ on stream. The IR spectra taken every 16 min during $n$-butane isomerization are displayed in Figure 5; the spectrum at the start of the reaction and the spectrum corresponding to the maximum rate are shown in black. The $\mathrm{OH}$ stretching band around $3580 \mathrm{~cm}^{-1}$ increases and C-H bands at 2966, 2938, 2873 (stretching modes), and $1465 \mathrm{~cm}^{-1}$ (deformation mode) become visible as soon as the feed gas is admitted to the cell. OH deformation bands of adsorbed water at 1602 and $1626 \mathrm{~cm}^{-1}$ increase with time on stream. For the $\mathrm{S}=\mathrm{O}$ band at $1402 \mathrm{~cm}^{-1}$ a shift towards lower wavenumbers and an intensity decrease are observed, while the $\mathrm{S}=\mathrm{O}$ band at $1303 \mathrm{~cm}^{-1}$ increases with time on stream (not shown).

The band area increase of the water feature including the bands at 1626 and $1602 \mathrm{~cm}^{-1}$ of $2.0 \mathrm{FeSZ}$ (see Figure 5) was determined from IR spectra by subtracting the area after activation from the area during the reaction. The simultaneously measured isobutane formation rate is plotted vs. the band area increase in Figure 6. To relate the transmission data of $2.0 \mathrm{FeSZ}$ to the results measured in diffuse reflectance using powder beds of $2.0 \mathrm{MnSZ}$ and unpromoted SZ [Figure 6], a reference point is needed. Before activation all calcined samples contain similar amounts of water, about $1.2-2.5 \mathrm{mmol} \mathrm{g}^{-1}$ according to thermogravimetric measurements. Thus, the initial band area in the $\mathrm{OH}$ deformation region on all samples before activation should correspond to the same amount of adsorbed water, independent of the set-up. The relative water content during reaction is obtained by dividing the band area increase during reaction by the initial band area before activation. Figure 6 suggests a linear correlation of rate and water content for all catalysts, whereby the isomerization rate increases from $\mathrm{SZ}<<2.0 \mathrm{FeSZ}<2.0 \mathrm{MnSZ}$ for the same water content.

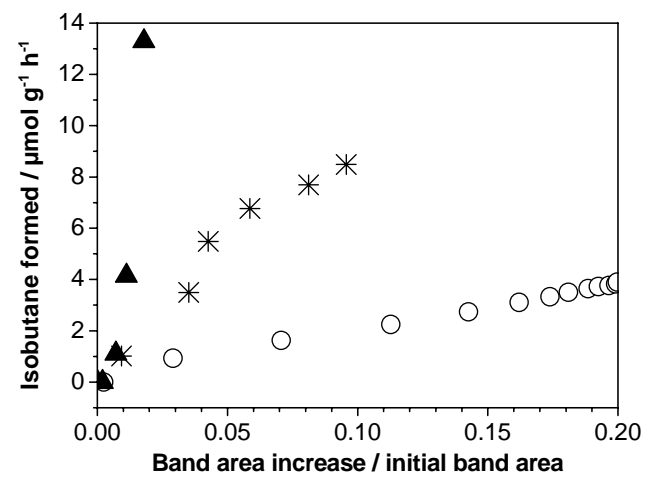

Figure 6: Isobutane formation rate vs. area increase of water IR band centered at $1650-1600 \mathrm{~cm}^{-1}$ during $n$-butane isomerization relative to the area of this feature before activation. 2.0FeSZ wafer in transmission (asterisk), 2.0MnSZ (solid triangle), and SZ powders (open circle) in diffuse reflection.

Adsorption of $\mathrm{CO}$ on 2.0FeSZ after activation in flowing $\mathrm{N}_{2}$ was monitored by IR spectroscopy; difference spectra created by subtracting the spectrum before from the spectrum after $\mathrm{CO}$ exposure. At low $\mathrm{CO}$ partial pressure only one band is visible at $2208 \mathrm{~cm}^{-1}$. With increasing partial pressure the band increases in intensity and is redshifted towards $2200 \mathrm{~cm}^{-1}$. At very high partial pressure of ca. $200 \mathrm{hPa} \mathrm{CO}$ a second band appears at $2162 \mathrm{~cm}^{-1}$. If 2.0FeSZ is activated in vacuum instead of in flowing $\mathrm{N}_{2}$, a band at ca. $2160 \mathrm{~cm}^{-1}$ forms already at a partial pressure of $5 \mathrm{hPa}$. The band increases in intensity and shifts to ca. $2155 \mathrm{~cm}^{-1}$ with increasing CO pressure (not shown).

To determine the actually available sites on the surface of $2.0 \mathrm{FeSZ}$ during reaction, the reaction was inter- 
rupted at different stages, i.e. at maximum conversion or after many hours on stream, and $\mathrm{CO}$ was adsorbed. In Figure 7a the catalytic data are displayed for three experiments with individual 2.0FeSZ wafers. The corresponding spectra in Figure $7 \mathrm{~b}$ at a partial pressure of $9 \mathrm{hPa}$ show that the intensity of the $\mathrm{CO}$ band at $2200 \mathrm{~cm}^{-1}$ decreases with time on stream.
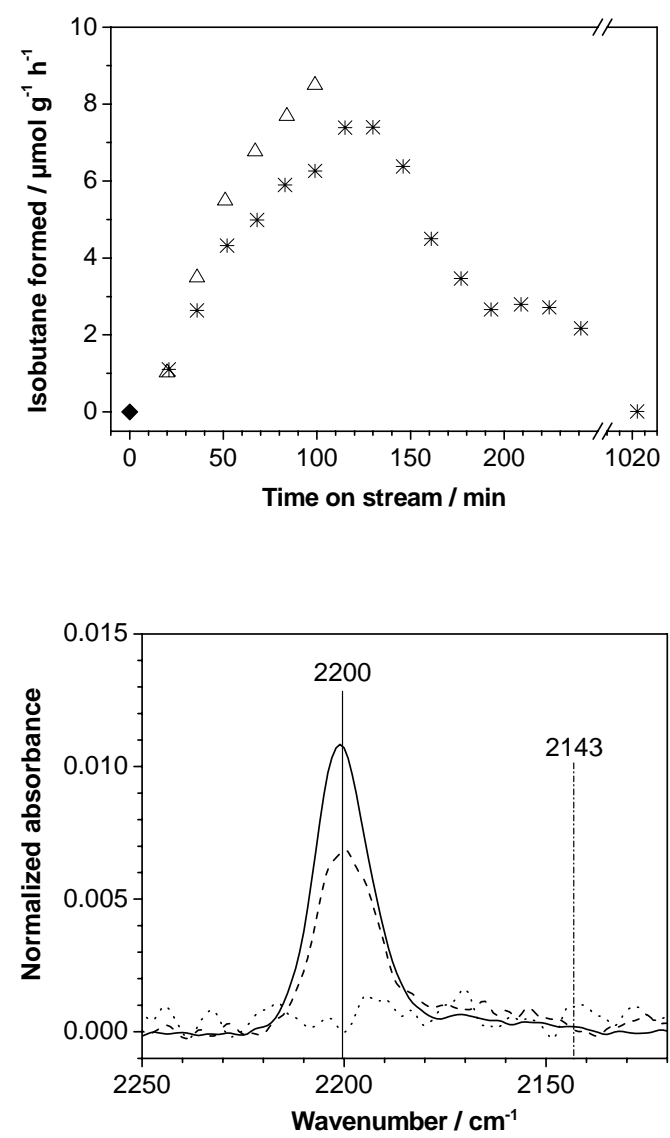

Figure 7: a) Rate of isomerization versus time on stream of $2.0 \mathrm{FeSZ}$ at $323 \mathrm{~K}$ and total flow of $30 \mathrm{ml} \mathrm{min}^{-1}$ of $1 \mathrm{kPa}$ butane in balance of $\mathrm{N}_{2}$ after activation in $40 \mathrm{ml} \mathrm{min}^{-1} \mathrm{~N}_{2}$ at $723 \mathrm{~K}$; b) FTIR spectra of $\mathrm{CO}$ adsorption at RT after reaction was stopped, pressure $9 \mathrm{hPa} C O$. For each of the three experiments a fresh wafer was used, spectra are normalized to wafer area weight. Activated catalyst: solid line \& solid diamond, stop after $100 \mathrm{~min}$ : dashed line \& open triangle, stop after $17 \mathrm{~h}$ : dotted line $\&$ asterisk.

\section{Discussion}

\subsection{Catalytic activation}

We have described DRIFT spectra of SZ, 2.0MnSZ, and 2.0FeSZ previously [6,17]. Several of the observed features are important for the discussion here. A strong decrease of the $\mathrm{OH}$ vibrations, especially of the characteristic combination of stretching and deformation modes of adsorbed water at around $5200 \mathrm{~cm}^{-1}$ evidences dehydration during activation. The $\mathrm{S}=\mathrm{O}$ stretching band located at $\approx 1400 \mathrm{~cm}^{-1}$ after activation indicates $\mathrm{S}_{2} \mathrm{O}_{7}{ }^{2-}$ according to DFT calculations [33]. The adsorbed-water content after activation in $\mathrm{N}_{2}$-flow was about $60-125 \mu \mathrm{mol} \mathrm{H}_{2} \mathrm{O} \mathrm{g} \mathrm{g}^{-1}$. Variation of the activation atmosphere had little effect on the SO and $\mathrm{OH}$ vibrations of $2.0 \mathrm{MnSZ}$. Strong Lewis acid sites capable of adsorbing $\mathrm{N}_{2}$ at temperatures up to $358 \mathrm{~K}$ were found.

Before the transmission FTIR measurements, 2.0FeSZ had to be pressed to form a self-supporting wafer, which can cause phase transformation [34]. If $2.0 \mathrm{FeSZ}$ is pressed for $10 \mathrm{~min}$ at $540 \mathrm{MPa}$, a fraction of the metastable tetragonal phase is transformed, leading to $20-30 \mathrm{wt} \%$ of the stable monoclinic form. In the experiments presented in this article, the wafer was pressed under less harsh conditions $(20 \mathrm{~s}$ at $270 \mathrm{MPa})$ to minimize the phase transformation. Transmission spectra of $2.0 \mathrm{FeSZ}$ after activation (Figure 5) confirm the results obtained by DRIFTS about the functional groups. The water loss of the $2.0 \mathrm{FeSZ}$ wafer during activation can be estimated from the decrease of the water deformation band at around $1600 \mathrm{~cm}^{-1}$ and amounts to $96 \%$, corresponding to a residual content of $45-93 \mu \mathrm{mol}$ $\mathrm{H}_{2} \mathrm{O} \mathrm{g}^{-1}$, which is comparable to the results obtained in the DRIFT cell.

The UV-vis spectra (Figure 1) give additional information about the Mn species in the catalysts. XRD and ion scattering spectroscopy had revealed a large fraction of dissolved $\mathrm{Mn}$ in the zirconia lattice [5]; X-ray absorption fine structure (XAFS) analysis had yielded an average oxidation state in calcined $2.0 \mathrm{MnSZ}$ of 2.7-2.8 [22], suggesting mixed valences. The band at $320 \mathrm{~nm}$ can be assigned to a charge transfer from $\mathrm{O}^{2-}$ to $\mathrm{Mn}^{3+}$ [35], the band at $690 \mathrm{~nm}$ to a d-d transition of $\mathrm{Mn}^{3+}$ [36]. A band around $555 \mathrm{~nm}$ has been attributed to a d-d transition of either $\mathrm{Mn}^{2+}$ or $\mathrm{Mn}^{3+}$ [37]. Even though $\mathrm{Mn}^{2+} \mathrm{d}-\mathrm{d}$ transitions are spin-forbidden [13] and thus weak, such transitions should contribute because $\mathrm{Mn}^{2+}$ is the only likely oxidation state in these catalysts that allows for an average valence $<3$. Hence, the Mnpromoted catalyst contains a mixture of $\mathrm{Mn}^{3+}$ and $\mathrm{Mn}^{2+}$ after calcination.

The Mn species are only slightly influenced by activation in oxidizing atmosphere (Figure 1b). Activation in He (Figure 1a) leads to a band at $410 \mathrm{~nm}$, which is close to the absorption of $\mathrm{Mn}^{2+}$ in an octahedral environment [38]. However, treatment of unpromoted SZ in inert gas also produces a (much weaker) band in this range (not shown), which has been assigned to a composite of absorptions by electron $\left(\mathrm{F}, \mathrm{F}^{+}\right.$and $\left.\mathrm{Zr}^{3+}\right)$ and hole (V) color centers [39]. A band at $485 \mathrm{~nm}$ has been assigned to $\mathrm{Mn}^{2+}$ in $\mathrm{MnO}$ [38], a band at $480 \mathrm{~nm}$ to $\mathrm{Mn}^{3+}$ in $\mathrm{Mn}_{2} \mathrm{O}_{3}$ [35], i.e. changes in this range are ambiguous. Significantly weakened are the two bands at 320 and $690 \mathrm{~nm}$, which are charge transfer and d-d transitions associated with $\mathrm{Mn}^{3+}$. In summary, these spectral changes are in favor of partial reduction of Mn during pretreatment and are consistent with XAFS measurements, which indicate only a slight decrease in the average $\mathrm{Mn}$ valence from 2.77 to 2.72 after activation in $50 \% \mathrm{O}_{2}$ and a pronounced reduction of $\mathrm{Mn}$ to an average valence of 2.55 
after activation in He [22]. Hence, after activation in different atmospheres the redox properties of the Mn-promoted catalyst should differ, while the functional groups such as sulfate and $\mathrm{OH}$ groups are in a comparable state [6].

\subsection{Catalyst start-up and performance}

In situ IR spectra of FeSZ (Figure 5) reveal an increase of the $\mathrm{OH}$ deformation bands at 1602 and $1626 \mathrm{~cm}^{-1}$ with time on stream, consistent with the formation of increasing amounts of water. More than one frequency may be observed because of water adsorption on different sites or, at higher degrees of hydration, due to association of water molecules [17]. For SZ and MnSZ, the rate of isomerization during the start-up has been found to be proportional to the area of the vibrational bands of water $[6,15]$ and Figure 6 demonstrates that this relationship also applies for FeSZ. The linear correlation between rate and number of water molecules is in favor of a reaction initiation via oxidative dehydrogenation of $n$-butane according to the following equation: oxidized catalyst $+\mathrm{C}_{4} \mathrm{H}_{10} \rightarrow \mathrm{C}_{4} \mathrm{H}_{8}+$ $\mathrm{H}_{2} \mathrm{O}+$ reduced catalyst. Assuming $\mathrm{ODH}$, one molecule $\mathrm{H}_{2} \mathrm{O}$ is formed per reactive intermediate (carbenium ion generated via protonation of butene). If all $\mathrm{H}_{2} \mathrm{O}$ molecules stick to the catalyst (reaction temperature: $323 \mathrm{~K}$ ), the number of absorbed water molecules is proportional to the number of chain carriers and in turn, the rate of isomerization is proportional to the number of these reactive intermediates.

Figure 6 reveals that for the same $\mathrm{H}_{2} \mathrm{O}$ deformation band-area increase the isomerization rate is not the same for 2.0MnSZ, 2.0FeSZ, and SZ. The differences between $\mathrm{Mn}$ - and Fe-promoted SZ may in part be ascribed to experimental circumstances: $2.0 \mathrm{MnSZ}$ was measured as a powder, 2.0FeSZ as a wafer. The observed lower rate of 2.0FeSZ may be due to mass transfer limitations in the wafer and partial monoclinization. However, the isobutane production per water molecule is much higher in the case of promoted catalysts. There are several potential reasons for this behavior, (i) assuming only a monomolecular mechanism, the actual turnover rate per site is higher, (ii) a higher site density favors the bimolecular mechanism with its lower activation energy [40] over the monomolecular mechanism, or (iii) there is another route to "active sites" (carbenium ions) without the formation of water, e.g. via protonation and cleavage of $\mathrm{H}_{2}$, which, however, has only been demonstrated for unpromoted sulfated zirconia [41].

Given that ODH is a major route of initiation, one would expect a highly oxidized state of the catalyst to be advantageous in providing oxidation equivalents, and possibly a highly hydrated state to be disadvantageous, because a driving force for water formation could be the energy that is released upon its adsorption on coordinatively unsaturated (cus) sites. Indeed, for $0.5 \mathrm{MnSZ}$, change of the activation atmosphere from inert to oxidizing leads to an increased activity followed by more rapid deactivation (Figure 2). The higher activity after activation in $\mathrm{O}_{2}$ - containing atmosphere is consistent with our previous results obtained in a DRIFTS [6] or a XAFS [22] in situ cell, and with the observations of Wan et al. [11] and of Song and Kydd [12] for Fe,Mn-promoted SZ. Because the Mn valence is also higher after activation in $\mathrm{O}_{2}$, one might want to attribute the increased activity to generation of a larger amount of reaction chain carriers via $\mathrm{ODH}$ with $\mathrm{Mn}$ as oxidizing agent. During the start-up period Mn should then be reduced in an extent that can be correlated with the achieved rate. The data (Figure 3 ) contradict such a scenario: for the catalyst activated in $\mathrm{O}_{2}$, a band characteristic for $\mathrm{Mn}^{2+}$ evolves at $410 \mathrm{~nm}$ with time on stream, indicating reduction of $\mathrm{Mn}$; but after activation in $\mathrm{He}$, the spectra of the reduced catalyst do not change during $13 \mathrm{~h}$ on stream, while conversion to isobutane is undergoing dramatic changes (Figure 2). Both observations are consistent with our previous XAFS results [22]. Start-up of the reaction is obviously possible without reduction of $\mathrm{Mn}$, nevertheless higher activity than that intrinsic to SZ is obtained. As proposed earlier $[6,15]$, sulfate is a likely oxidizing agent. The activation atmosphere has been reported to not affect the performance of unpromoted SZ [12], suggesting that Sspecies are immune to reduction (or oxidation) under these conditions; however, $\mathrm{SO}_{2}$ evolution during activation in $\mathrm{He}$ has been reported [15]. The effect on the promoted catalysts could be explained as follows: TPD experiments with various bases $[11,42]$ and also test reactions with $\mathrm{H}_{2}$ and butane [6] showed that promoters render sulfate more susceptible to reduction. During activation in inert gas, along with the $\mathrm{Mn}$, a fraction (the most reactive fraction) of the sulfate might be reduced, diminishing the resulting activity. DRIFT spectra however show no significant differences after activation in different atmospheres [6]. Another effect that could contribute to the better performance after activation in oxidizing atmosphere is removal of ubiquitous carbon contaminations, making more sites available and enhancing the activity. This should also apply for unpromoted SZ, and, in contrast to literature reports, preliminary experiments in our laboratory suggest that SZ might be slightly more active after activation in $\mathrm{O}_{2}$ than after activation in $\mathrm{He}$ [43].

No general statement can be made about the influence of the hydration state. Song and Kydd had found small amounts of water to have a positive, large amounts to have a negative effect on the performance of SZ [12]; best performance was reported for $200 \mu \mathrm{mol} \mathrm{g}^{-1}$ [44]. González et al. inferred that a water concentration of $75 \mu \mathrm{mol} \mathrm{g}{ }^{-1}$ is optimal [45], while we found that small variations of the water content by $2.5-5 \%$, clearly visible in IR spectra, did not affect the catalytic performance of $2.0 \mathrm{MnSZ}$ [6].

\subsection{Adsorption sites and surface hydrocarbon species}

The $\mathrm{CO}$ adsorption data demonstrate that the 2.0FeSZ catalyst surface provides Lewis sites. The band appearing at $2208 \mathrm{~cm}^{-1}$ can be assigned to a stretching vi- 
bration of $\mathrm{CO}$ interacting with cus $\mathrm{Zr}^{4+}$ sites; a band at the same position has been reported for monoclinic or partly tetragonal SZ $[46,47]$. Pinna et al. found the band of CO adsorbed on cus $\mathrm{Zr}^{4+}$ on $\mathrm{SZ}$ to be shifted from 2200 to 2210 $\mathrm{cm}^{-1}$ with the $\mathrm{CO}$ partial pressure decreasing from $133 \mathrm{hPa}-1.6 \mathrm{~Pa}$ [48]. Consistent with the literature [8-10], promotion does not increase the (Lewis) acid strength. We presume these cus $\mathrm{Zr}^{4+}$ sites are responsible also for adsorption of $\mathrm{N}_{2}$ at room temperature in $1 \mathrm{~atm} \mathrm{~N}_{2}$, which we have reported earlier [6]. Because iron is not very well incorporated into the zirconia lattice but accumulates on the surface [5], CO could also interact with cus $\mathrm{Fe}^{\mathrm{x}+}$ species. $\mathrm{CO}$ at cus $\mathrm{Fe}^{3+}$ has been reported to show bands at 2150, 2138, and $2124 \mathrm{~cm}^{-1}$ for Fe-containing zirconia [49], while $\mathrm{Fe}^{\mathrm{x}+}$ $(\mathrm{x}<3)$ was found to show a band at $2170 \mathrm{~cm}^{-1}$ for $\mathrm{Fe}-$ promoted SZ [50]. The CO band appearing around 2160 $\mathrm{cm}^{-1}$ at high partial pressure can thus be attributed to $\mathrm{CO}$ on Lewis acidic iron species.

Concerning interaction of $2.0 \mathrm{FeSZ}$ with butane, the data recorded on $2.0 \mathrm{FeSZ}$ in transmission in the catalytic flow experiment at $323 \mathrm{~K}$ agree quite well with the results of the room temperature adsorption measured with DRIFTS. The data quality in transmission is inferior in comparison to DRIFTS due to low transmittance of the SZ samples. In both cases, the $\mathrm{OH}$ band at ca. $3632-3634 \mathrm{~cm}^{-1}$ is shifted, more so in the DRIFTS than in the transmission experiment ( 65 vs. $53 \mathrm{~cm}^{-1}$ ) because of the higher butane pressure $(100$ vs. $10 \mathrm{hPa})$. These results prove interaction of butane with $\mathrm{OH}$ groups, viz. Brønsted sites. At $100 \mathrm{hPa}$ the shift is slightly larger for $2.0 \mathrm{FeSZ}$ than for SZ $\left(53 \mathrm{~cm}^{-1}\right.$, Figure 4a); however, the $\mathrm{OH}$ vibrations are much more intense for $\mathrm{SZ}$ and at equal partial pressure, the population of $\mathrm{OH}$ sites with butane might be lower for SZ, resulting in a shift comparable to that observed for $2.0 \mathrm{FeSZ}$ at lower partial pressure. The weak and upon evacuation mostly reversible shift is consistent with the low heats of alkane adsorption of 45-60 $\mathrm{kJ} \mathrm{mol}^{-1}$ measured for the majority of sites on these catalysts $[26,51]$. A red-shift of the $\mathrm{S}=\mathrm{O}$ vibration as seen from the decrease of the band at $2765 \mathrm{~cm}^{-1}$ and the concomitant appearance of a band at $2745 \mathrm{~cm}^{-1}$ in the difference spectra (Figure 4c) indicates interaction of butane not only with $\mathrm{OH}$ but also with sulfate groups.

The observed $\mathrm{CH}$ stretching vibrations in butane atmosphere also agree to a large extent in the DRIFTS and the transmission experiments performed using 2.0FeSZ. Stretching and deformation vibrations of $n$-butane can be seen at 2966, 2938, 2875 and $1466 \mathrm{~cm}^{-1}$ (Figure 4c) vs. 2965, 2938, 2873, and $1465 \mathrm{~cm}^{-1}$ (Figure 5). These bands represent $v_{a s}\left(\mathrm{CH}_{3}\right), v_{\text {as }}\left(\mathrm{CH}_{2}\right)$, partially resolved $v_{\mathrm{s}}\left(\mathrm{CH}_{3}\right)$ and $v_{\mathrm{s}}\left(\mathrm{CH}_{2}\right)$, and $\delta\left(\mathrm{CH}_{3}, \mathrm{CH}_{2}\right)$ vibrations; the bands are broader and the symmetric stretching vibrations have a stronger relative intensity than in the gas phase butane spectrum. After removal of weakly adsorbed species by evacuation, a band at $2909 \mathrm{~cm}^{-1}$ can be discerned in the DRIFT spectra of 2.0FeSZ. The frequency is characteristic of $\mathrm{CH}$ stretching vibrations of methyne groups, indicating the formation of isomerized species on the surface of $2.0 \mathrm{FeSZ}$ at room temperature. Such a band is not present for SZ, once more confirming the higher reactivity of promoted SZ at lower temperatures. Interestingly, no bands of water could be detected in the spectra of $2.0 \mathrm{FeSZ}$ in this room temperature batch experiment, suggesting that another channel of butane activation besides ODH may exist. Again, an additional mechanism would provide an explanation for a higher rate per formed water molecule for promoted compared to unpromoted SZ (Figure 6); however, it is difficult to explain why the rate should still be roughly proportional to the amount of water formed.

Both the spectra of $\mathrm{SZ}$ and $2.0 \mathrm{FeSZ}$ exhibit further bands at $2820-2840 \mathrm{~cm}^{-1}$. This frequency is close to that of $\mathrm{CH}$ vibrations in ethers, which lie below $2850 \mathrm{~cm}^{-1}$. According to the supposed mechanism, isomerization of $n$-butane proceeds via carbenium ion type species [52-54]. Adsorbed carbenium ions can be expected to form ester or ether (alkoxide)-like structures with surface oxygen of the catalyst, analogous to solution chemistry [55]. The observed bands could represent such stable alkoxide species, which cannot desorb without hydride transfer from an incoming butane molecule or proton elimination (at higher temperature?). Weakening of the symmetric $\mathrm{CH}$ stretching vibrations due to hydrogen bond formation is another possible explanation for these broad low frequency bands. These species absorb at $10-20 \mathrm{~cm}^{-1}$ lower frequency on 2.0FeSZ than on SZ, indicating that at least a fraction experiences a different inductive effect by the bridge to the surface. Hence the electronic properties of the reactive surface sites are slightly different on these materials.

\subsection{Catalyst deactivation}

At different stages of catalytic activity, Lewis sites on the catalysts were probed by $\mathrm{CO}$ adsorption at room temperature (Figure 7). At the same CO partial pressure of $9 \mathrm{hPa}$ the band indicative of $\mathrm{CO}$ at Lewis sites is less intense after reaching the maximum rate than at the start of the reaction and has vanished after running the reaction for $17 \mathrm{~h}$ (Figure 7). The capacity of $2.0 \mathrm{FeSZ}$ to adsorb $\mathrm{CO}$ on $\mathrm{Zr}^{4+}$ Lewis sites decreases with time on stream and the amount of adsorbed $\mathrm{CO}$ can thus not be taken as a measure for the catalytic activity of $2.0 \mathrm{FeSZ}$ in the present state. $\mathrm{CO}$ is a poison that inhibits isobutane formation as long as it is added to the feed $[48,56]$; instead of blocking active Lewis sites that are necessary for isomerization [48], it is reacting with the adsorbed carbenium ions [56,57], so that their transformation to isobutane is hindered. Our adsorption experiments show that $\mathrm{Zr}^{4+}$ sites that are able to interact with $\mathrm{CO}$ are blocked during $n$-butane isomerization. Either the reactant or its product or byproducts could be responsible for the consumption of Lewis sites. From the spectra recorded in situ during $n$-butane isomerization (Figure 5), it is clear that water is formed. Because of its high electron density (free electron pairs) water is a much stronger Lewis base than alkanes. Thus, it is the water that adsorbs on 2.0FeSZ and blocks the Lewis sites. The activity increases while Lewis sites are already being blocked and decreases 
before all Lewis sites are covered with water (cf. Figs. 7a and $7 \mathrm{~b}$ ).

In the ODH activation scheme, one would expect the rate to level off once all active sites have reacted to produce water, a "carbenium ion" and a reduced catalyst site. Deactivation can only occur if any of the reaction steps during initiation, isomerization or hydride transfer does not proceed with $100 \%$ selectivity. The water formed during initiation adheres to the surface and could poison unreacted sites, but this should only lead to a lower maximum but not to a declining rate. Water can only be considered as a cause for deactivation, as inferred before $[23,58]$, if it originates from other sources than $\mathrm{ODH}$. We have previously found minor changes in the degree of hydration to have no effect on the catalytic performance [6].

The UV-vis spectra during isomerization over Heactivated $0.5 \mathrm{MnSZ}$ reveal (Figure 3a) that $\mathrm{Mn}$ is not reduced during reaction. The reduction observed after activation in $\mathrm{O}_{2}$ occurs slowly and appears not related to the catalytic performance (Figures 2 and $3 b$ ). These observations are consistent with previous results on the Mn valence in 2.0MnSZ obtained with in situ XAFS spectroscopy [22]. A slow dying-out of the isomerization, because of side reactions and the lack of redox-active promoter species to initiate new cycles as proposed by Wan et al. [11] or Millet et al. [20] for Fe-promoted material, is excluded for Mn. This observation supports the idea that the oxidizing species for ODH is sulfate.

The side reactions that are responsible for deactivation are likely those producing stable carbon-containing surface species. In earlier work on the $n$-butane isomerization in the presence of SZ, a band at about 295-305 nm was assigned to allylic cations $[16.59,60]$ and taken as an indication of unsaturated hydrocarbon deposits, which deactivate the catalyst. No comparable band is formed during isomerization with $0.5 \mathrm{MnSZ}$, independent of the preceding activation procedure (Figure 3), raising the question as to why this catalyst deactivates so rapidly (Figure 2). IR spectra of MnSZ deactivated at $323 \mathrm{~K}$ were obscured by hydrogen bonding in the $\mathrm{CH}$ range so that deposits could not be identified, even after purging the feed gas from the reaction cell [6]. Heating to $773 \mathrm{~K}$ resulted in distinct bands characteristic of unsaturated hydrocarbon surface species [6], indicating that irreversibly adsorbed species had been present after reaction. The data obtained here for SZ and FeSZ suggest that strongly held species generated at low temperatures are of saturated nature. In this sense, we can currently not distinguish whether the species absorbing at $2820-2840 \mathrm{~cm}^{-1}$, tentatively assigned to alkoxides, are intermediates and reaction chain carriers or "dead-end" stable side products.

\subsection{Solid state chemistry and sites}

Sulfated zirconia materials are superior for $n$-butane isomerization than are other sulfated oxides [61], and tetragonal zirconia is more active than monoclinic zirconia [25]. The support structure and electronic properties thus determine the reactivity of the sulfate and the properties of the adsorption sites and potentially of other "assisting" sites. Many cations have been identified as promoters for sulfated zirconia, e.g. ions of $\mathrm{V}, \mathrm{Cr}, \mathrm{Mn}, \mathrm{Fe}, \mathrm{Co}, \mathrm{Ni}, \mathrm{Al}$, or $\mathrm{Ga}[2,4,62-66]$. The product distributions are very similar for differently promoted catalysts [4] and seem to depend more on the conversion than on the nature of these cations. One explanation for this behavior could be that the action of the promoters is such that their individual chemistry is of secondary importance. All of these ions (can) have a lower valence than the $\mathrm{Zr}^{4+}$, and ions of $\mathrm{V}, \mathrm{Cr}, \mathrm{Mn}, \mathrm{Fe}, \mathrm{Co}, \mathrm{Ni}$, and $\mathrm{Al}$ can be dissolved in the zirconia lattice [5,67]. A consequence of the incorporation of these aliovalent ions is stabilization and variation of the lattice constants of the tetragonal phase, and for charge balance, defects such as oxygen vacancies have to be generated. Such a scenario is depicted in Scheme 1. The changes in geometric and electronic structure in the zirconia bulk and near-surface regions that are caused by the promotion will affect the surface sites ("star" in scheme, representing any type of site such as cus metal cation, $\mathrm{OH}$ group, or sulfate). Lewis and Brønsted acid strength sites were not significantly altered through the promotion (this work,8-10,17) but the reactivity of sulfate was found to be increased [17]. The fact that all promoters are similar in their influence on the catalytic behavior suggests that the dissolved species and the generated lattice defects (e.g. anion vacancies) are responsible for the promotional effect and not surface promoter oxide species, which would be quite different in nature for the listed promoters. Further evidence for the importance of isolated promoter ions vs. a promoter oxide phase is the fact that $\mathrm{Mn}$ is extremely well dispersed and incorporated and exerts a considerable effect already at a concentration as low as $0.5 \mathrm{wt} \%[5,30]$. Also, this model would explain the reactivity of unpromoted $\mathrm{SZ}$ if $\mathrm{M}^{\mathrm{x}+}$ in Scheme 1 is $\mathrm{Zr}^{3+}$, i.e. the role of the promoter is taken over by $\mathrm{Zr}^{3+}$. However, the concentration of $\mathrm{Zr}^{3+}$ in a normal unpromoted $\mathrm{SZ}$ is presumably lower than a typical promoter concentration, resulting in fewer sites. The slight variations that result for different ions (e.g. $\mathrm{Fe}^{3+}$ and $\mathrm{Zr}^{3+}$ ) could be the reason for the different frequencies of the "alkoxide" species for SZ and Fe-promoted SZ. Further support for this model and the importance of oxygen vacancies can be summoned from the work of Vera et al. [68], who showed that partial reduction of the zirconia-support prior to addition of sulfate resulted in a more active catalyst. 
Scheme 1: Simplified representation of formation of active site. As so many zirconia bulk properties are relevant for the catalytic performance, it appears that the active site or an assisting site is connected to a specific feature of the bulk.

$\mathrm{M}^{\mathrm{x}+}$ : promoter or $\mathrm{Zr}$ with $\mathrm{x}<4$; $\square$ : $\mathrm{O}$ vacancy; star: active site

References in brackets.

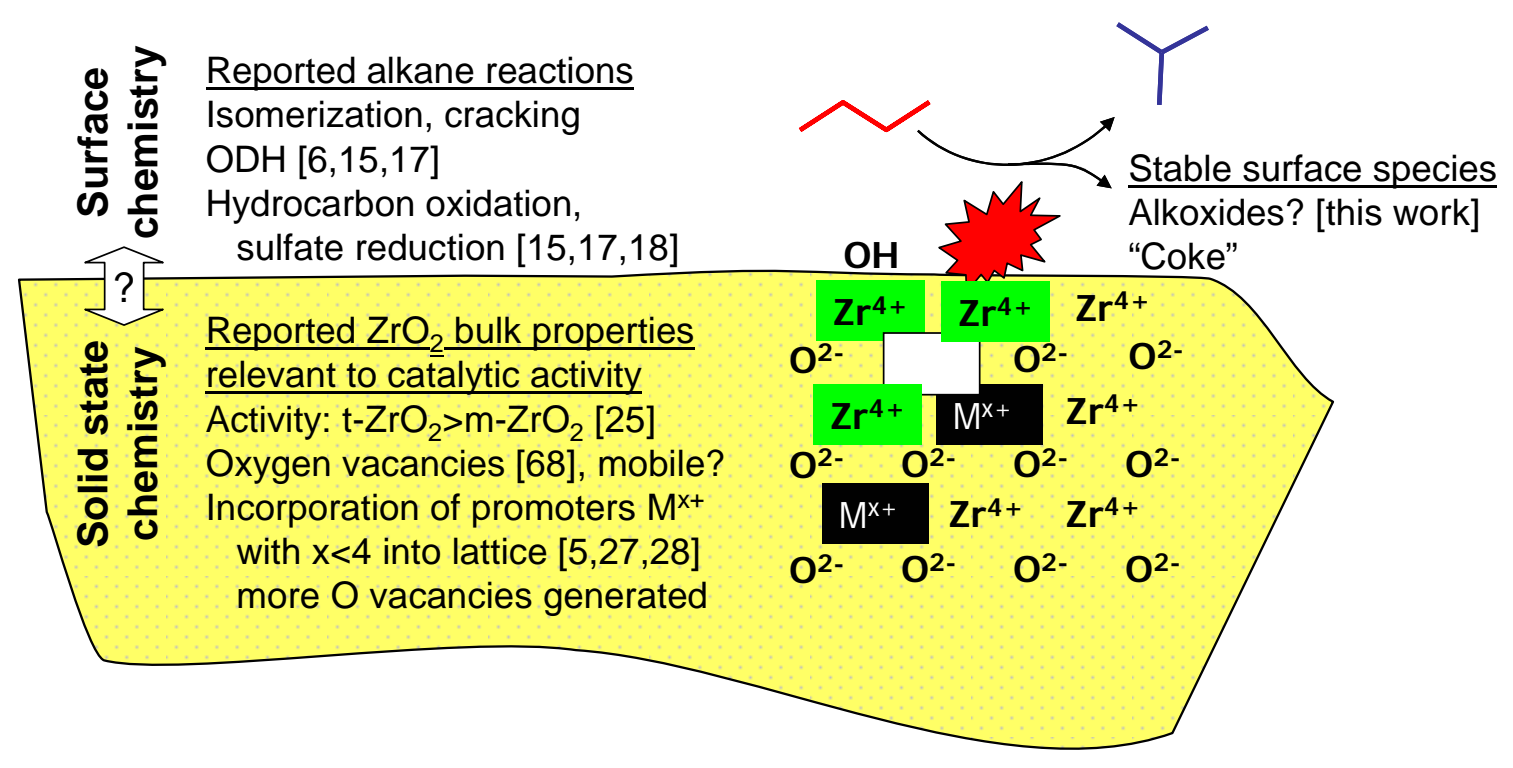

\section{Conclusions and Outlook}

Investigation of the amount of water on the surface of SZ, Mn-promoted SZ, and Fe-promoted SZ during $n$ butane isomerization gives a consistent picture [6, this work]: during the start-up of the catalyst, the isomerization rate increases with the amount of water that is being formed. This scenario is consistent with an activation of $n$ butane via ODH, which leads to the formation of a reaction chain carrier ("carbenium-ion-like"), water and a reduced catalyst species. Sulfate is the most likely oxidizing agent, because activity is observed for Mn-promoted SZ without reduction of $\mathrm{Mn}$ and also for unpromoted SZ. Activation in inert gas may have the disadvantage of reduction of a fraction of the most active sulfate [15] and will thus lead to a poorer performance than activation in an oxidizing atmosphere. This effect is more pronounced in the presence of promoters, which make the sulfate more susceptible to reduction [17]. Isomerized species were also found on the surface of Fe-promoted SZ after exposure to $n$-butane while water formation was not detected, and hence there seem to be other initiation pathways besides $\mathrm{ODH}$, at least for this promoted catalyst.

Stable alkoxide-like species absorbing at 2820-2840 $\mathrm{cm}^{-1}$ were detected on the surface of SZ and Fe-promoted SZ after contact with $n$-butane; it is not understood whether they are side-products or intermediates. The nature of these surface species was slightly different on the two catalysts, reflecting the different structural and electronic properties of the unpromoted and promoted SZ. It is suggested that near-surface defect states are generated by promoters ions dissolved in the zirconia lattice. These defects determine the support properties. This model would hold for many different promoters. In the future, this link between solid state chemistry, i.e. the nature of the defects, and the surface chemistry will have to be elucidated.

\section{Acknowledgements}

Barbara S. Klose, Annette Trunschke, and the cooperation between MPG and RAS were kindly supported by DFG grants JE 267/2-1 and 436 RUS 113/788/0-1. The authors thank Gisela Lorenz for assistance with the catalyst preparation, Carla Tschentscher and Heinz Junkes for developing the software to control the Lambda 9 spectrometer, and Rolf E. Jentoft for thermogravimetric measurements. 


\section{References}

[1] M. Hino, S. Kobayashi and K. Arata, J. Am. Chem. Soc., 101 (1979) 6439.

[2] M. Hino and K. Arata, J. Chem. Soc. Chem. Commun., (1980) 851.

[3] C.-Y. Hsu, C.R. Heimbuch, C.T. Armes and B.C. Gates, J. Chem. Soc. Chem. Comm., (1992) 1645.

[4] F.C. Lange, T.-K. Cheung and B.C. Gates, Catal. Lett., 41 (1996) 95.

[5] F.C. Jentoft, A. Hahn, J. Kröhnert, G. Lorenz, R.E. Jentoft, T. Ressler, U. Wild, R. Schlögl, C. Häßner and K. Köhler, J. Catal., 224 (2004) 124.

[6] B.S. Klose, F.C. Jentoft and R. Schlögl, J. Catal., 233 (2005) 68.

[7] C.-H. Lin and C.-Y. Hsu, J. Chem. Soc. Chem. Comm., (1992) 1479.

[8] V. Adeeva, J.W. de Haan, J. Jänchen, G.D. Lei, V. Schünemann, L.J.M. van de Ven, W.M.H. Sachtler and R.A. van Santen, J. Catal., 151 (1995) 364.

[9] J.E. Tábora and R.J. Davis, J. Chem. Soc. Faraday Trans., 91 (1995) 1825.

[10] R.S. Drago and N. Kob, J. Phys. Chem. B, 101 (1997) 3360.

[11] K.T. Wan, C.B. Khouw and M.E. Davis, J. Catal., 158 (1996) 311.

[12] S.X. Song and R.A. Kydd, Catal. Lett., 51 (1998) 95.

[13] T.-K. Cheung, J.L. d'Itri and B.C. Gates, J. Catal., 151 (1995) 464.

[14] T.-K. Cheung, J.L. d'Itri and B.C. Gates, J. Catal., 153 (1995) 344.

[15] X. Li, K. Nagaoka, L.J. Simon, R. Olindo, J.A. Lercher, A. Hofmann and J. Sauer, J. Am. Chem. Soc., 127 (2005) 16159.

[16] R. Ahmad, J. Melsheimer, F.C. Jentoft and R. Schlögl, J. Catal., 218 (2003) 365.

[17] B.S. Klose, F.C. Jentoft, R. Schlögl, I.R. Subbotina and V.B. Kazansky, Langmuir, 21 (2005) 10564.

[18] F.T.T. Ng and N. Horvát, Appl. Catal. A: General, 123 (1995) L197.

[19] M.V. Luzgin, K. Thomas, J. van Gestel, J.-P. Gilson and A.G. Stepanov, J. Catal., 223 (2004) 290.

[20] J.M.M. Millet, M. Signoretto and P. Bonville, Catal. Lett., 64 (2000) 135 .

[21] T. Yamamoto, T. Tanaka, S. Takenaka, S. Yoshida, T. Onari, Y. Takahashi, T. Kosaka, S. Hasegawa and M. Kudo, J. Phys. Chem. B, 103 (1999) 2385.

[22] R.E. Jentoft, A.H.P. Hahn, F.C. Jentoft and T. Ressler, Phys. Chem. Chem. Phys., 7 (2005) 2830.

[23] R.A. Comelli, C.R. Vera and J.M. Parera, J. Catal., 151 (1995) 96.

[24] C. Morterra, G. Cerrato, F. Pinna, M. Signoretto and G. Strukul, J. Catal., 149 (1994) 181

[25] W. Stichert and F. Schüth, J. Catal., 174 (1998) 242.

[26] X. Li, K. Nagaoka, L.J. Simon, J.A. Lercher, S. Wrabetz, F.C. Jentoft, C. Breitkopf, S. Matysik and H. Papp, J. Catal., 230 (2005) 214.

[27] H. Ohtsuka, Catal. Lett., 90 (2003) 213.

[28] X. Carrier, P. Povilas, S. Kuba, L. Stievano, F.E. Wagner, M. Che and H. Knözinger, Chem. Phys. Chem., 5 (2004) 1191.

[29] A. Hahn, T. Ressler, R.E. Jentoft and F.C. Jentoft, Chem. Commun., (2001) 537.

[30] A.H.P. Hahn, R.E. Jentoft, T. Ressler, G. Weinberg, R. Schlögl and F.C. Jentoft, J. Catal., 236 (2005) 324

[31] V.B. Kazansky, V.Yu. Borovkov and H.G. Karge, J. Chem. Soc. Faraday Trans., 93 (1997) 1843.

[32] H. Bludau, W. Nießen and H. G. Karge, Microp. Mesop. Materials, 22 (1998) 297.
[33] A. Hofmann and J. Sauer, J. Phys. Chem. B, 108 (2004) 14652; personal communication.

[34] B.S. Klose, R.E. Jentoft, A. Hahn, T. Ressler, J. Kröhnert, S. Wrabetz, X. Yang and F.C. Jentoft, J. Catal., 217 (2003) 487.

[35] F. Milella, J.M. Gallardo-Amores, M. Baldi and G. Busca, J. Mater. Chem., 8 (1998) 2525.

[36] E. Fernández López, V. Sánchez Escribano, C. Resini, J.M. Gallardo-Amores and G. Busca, Appl. Catal. B: Environmental, 29 (2001) 251.

[37] W. Sjoerd Kijlstra, E.K. Poels, A. Bliek, B.M. Weckhuysen and R.A. Schoonheydt, J. Phys. Chem. B, 101 (1997) 309.

[38] G.W. Pratt, Jr., Phys. Rev., 2 (1959) 281.

[39] A. Emeline, G.V. Kataeva, A.S. Litke, A.V. Rudakova, V.K. Ryabchuk and N. Serpone, Langmuir, 14 (1998) 5011.

[40] H. Matsuhashi, H. Shibata, H. Nakamura and K. Arata, Appl. Catal. A: General, 187 (1999) 99.

[41] Z. Hong, K.B. Fogash, R.M. Watwe, B. Kim, B.I. MasquedaJiménez, M.A. Natal-Santiago, J.M Hill, J.A. Dumesic, J. Catal., 178 (1998) 489.

[42] A. Jatia, C. Chang, J.D. MacLeod, T. Okubo and M.E. Davis, Catal. Lett., 25 (1994) 21.

[43] C. Chan Thaw, F. Garin, G. Tzolova-Müller and F.C. Jentoft, unpublished results.

[44] S.X. Song and R.A. Kydd, J. Chem. Soc. Faraday Trans., 94 (1998) 1333.

[45] M.R. González, J.M. Kobe, K.B. Fogash and J.A. Dumesic, J. Catal., 160 (1996) 290.

[46] V. Bolis, C. Morterra, B. Fubini, P. Ugliengo and E. Garrone, Langmuir, 9 (1993) 1521.

[47] Z.T. Feng, W.S. Postula, C. Erkey, C.V. Philip, A. Akgerman and R.G. Anthony , J. Catal., 148 (1994) 84.

[48] F. Pinna, M. Signoretto, G. Strukul, G. Cerrato and C. Morterra, Catal. Lett., 26 (1994) 339.

[49] E. Guglielminotti, J. Phys. Chem., 98 (1994) 4884.

[50] C. Morterra, G. Cerrato, S. Di Ciero, M. Signorotto, A. Minesso, F. Pinna and G. Strukul, Catal. Lett., 49 (1997) 25.

[51] F.C. Jentoft, Habilitation Thesis, Humboldt-Universität zu Berlin (2005).

[52] D.M. Brouwer, in R. Prins and G.C.A. Schuit (Editors), Chemistry and Chemical Engineering of Catalytic Processes, NATO ASI Ser. E, No. 39, Sijthoff and Noordhoff, Alphen aan den Rijn, The Netherlands, 1980, p. 137.

[53] G.A. Olah, Y. Halpern, J. Shen and Y.K. Mo, J. Am. Chem. Soc., 95 (1973) 4960.

[54] C.D. Nentitzescu and I.P. Cantuniari, Ber. Dtsch. Chem. Ges., 66 (1933) 10907.

[55] M.V. Frash, V.N. Solkan and V.B. Kazansky, J. Chem. Soc., Faraday Trans., 93 (1997) 515.

[56] S. Hammache and J.G. Goodwin Jr., J. Catal., 218 (2003), 258.

[57] V. Adeeva, H.-Y. Liu, B.-Q. Xu and W.M.H. Sachtler, Top. Catal., 6 (1998), 61

[58] C. Morterra, G. Cerrato, F. Pinna, M. Signoretto and G. Strukul, J. Catal., 149 (1994) 181.

[59] F.R. Chen, G. Coudurier, J.-F. Joly and J.C. Védrine, J. Catal., 143 (1993) 616.

[60] D. Spielbauer, G.A.H. Mekhemer, E. Bosch, H. Knözinger, Catal. Lett., 36 (1996) 59.

[61] T. Yamaguchi, Appl. Catal., 61 (1990) 1.

[62] C. Miao, W. Hua, J. Chen and Z. Gao, Catal. Lett., 37 (1996) 187.

[63] M.A. Coelho, D.E. Resasco, E.C. Sikabwe and R.L. White, Catal. Lett., 32 (1995) 253. 
[64] M. Signoretto, S. Melada, F. Pinna, S. Polizzi, G. Cerrato and C. Morterra, Microp. Mesop. Materials, 81 (2005) 19.

[65] Z. Gao, Y. Xia, W. Hua and C. Miao, Top. Catal., 6 (1998) 101.

[66] M. Perez-Luna, A. Cosultchi, J. Toledo-Antonio and E. AreeEstrada, Catal. Lett., 102 (2005) 33.
[67] J. Stöcker, Ann. Chim., 5 (1960) 1459.

[68] C.R. Vera, C.L. Pieck, K. Shimizu and J.M. Parera, Appl. Catal. A: General, 230 (2002) 137. 